\title{
The Effect of Plyometric Trainings on Vertical-Horizontal Jump and Some Motor Skills in U13 Basketball Players
}

\author{
Mine Gül ${ }^{1}$, Kemal Gazanfer Güll${ }^{1}$, Ömer Ataç1 \\ ${ }^{1}$ Sports Science Faculty, Kocaeli University, Izmit, Turkey \\ Correspondence: Mine Gul, Sports Science Faculty, Kocaeli University, Izmit, Turkey.
}

Received: May 5, 2019 Accepted: May 8, $2019 \quad$ Online Published: May 20, 2019

doi:10.11114/jets.v7i7.4252 URL: https://doi.org/10.11114/jets.v7i7.4252

\begin{abstract}
The aim of this study was to determine the effects of Plyometric training on vertical-horizontal jump and some motor skills for children aged 13 years who play basketball. In this study voluntary 20 male athletes playing at 23 Nisan Sports Club as aged 13 basketball team whose ages are 13,00 \pm 0 (year), body weight 53,86 $\pm 9,31(\mathrm{~kg})$, the average size of $162,5 \pm 9,68(\mathrm{~cm})$ and body indexes of $20,34 \pm 2,77 \mathrm{~kg} / \mathrm{m}^{2}$ participated. All athletes were tested on the first measurements, after randomly divided into control $(n=7)$ and experimental $(n=7)$ groups. 2 days/week during 8 weeks, while the control group was doing basketball training only; the experimental group performed plyometric jump work in addition to basketball technique - tactical training, in the last 15 minutes of the training. All players height, body weight, vertical jump, horizontal jump, hand grip performance and elasticity performance tests were obtained at the beginning and end of the study; by these data using SPSS 18,0 programme with 0,05 significance level, Wilcoxon within group and Mann Withney-U statistical analysis was performed. There was no statistically significant difference in all the variables $p>0.05$ level between first and last measurements of the control and experimental groups. In this study, it was understood that the effect of 15-minute plyometric program in basketball technique-tactical training for 2 days/week for 8 weeks in 13 years age group basketball players, vertical-horizontal jumping, hand grip, seated reach\& extended flexibility test measurements has no effects.
\end{abstract}

Keywords: basketball, plyometric, jump, motor skills

\section{Introduction}

The main objective of all athletes and coaches is to achieve high performance by using scientific principles. Various types of the muscle enhancer exercise types' effects, muscle fibre types, muscle biochemistry, increasing the knowledge about the nerve muscle response, provides new opportunities for coaches to better train the athlete (Atesoglu, 2007). Trainers should regularly focus on improving the physical characteristics of athletes in each unit training. The development in millisecond reaction times and short distance velocity values will contribute to the athlete in the competition (Salonikidis and Zafeiridis, 2008). The place of jump training in speed training is very important. Sports scientists joined on the opinion together that during the second period of the basic training period of young athletes should include leap drills by appropriate periods (Dündar, 1990). The motor characteristics required for each sport branch vary from one branch to another. Basketball coaches attach importance to new methods and plyometric training that accelerate the muscle response because they believe that vertical jump and leg strength are the basis of superior performance (Ermiş, 2002). It has been found that plyometric training improves the strength performance and is also beneficial for athletes with and without fitness (Villarreal et al., 2010), which is related to the elastic strength of the first target in training; The importance of plyometric training is emphasized by the fact that the muscle can produce a large amount of work after concentric contraction with eccentric contraction. With the contraction that occurs quite quickly, the adaptation from the nerve muscle system will increase and elastic strength will develop. Physiological importance of the implementation of these exercises; to develop the energy of motion (kinetic energy) and force effectively to develop explosive force in splashing (Ermiş, 2002; Bavli, 2009; Göllü, 2006). In addition, the application of the plyometric study method should be paid attention to the characteristics of the age and the developmental stages of the athletes. Plyometric exercises are generally a better resulted method for elite athletes. Because, the first prerequisite is that the musculoskeletal system should be adequate for plyometric exercises. It is stated that it should not be applied in age groups who did not reach this development stage and non-conditioned athletes (Yüksel, 2006). It is thought that plyometric training has a significant effect on standard vertical jumping performance, can grow at the rate of $4-8 \%$ on 
average in jump heights and contributes to the development of physical fitness in healthy individuals (Markovic, 2007). In the literature surveys of plyometric training did not show any change in terms of values between the training sessions performed with less than 8 weeks\& with more frequent periods, by terms of the weeks applied, and plyometric trainings performed as 1 to 3 days per week does not show significant difference, however, the results was observed that the CMJ values of the weekly training frequency were affected after plyometric training. In addition to this, it was determined that resting between repeated exercises, the rest values between sets was found to be a significant difference (Slimani et al., 2017).

\section{Methodology}

\subsection{Research Group}

This study was carried out with the participation of 20 volunteers from the male athletes who played in the U13 leagues of the İzmit 23 Nisan Sports Basketball Club. It is divided into two groups and followings were detected: the mean age of the experimental group was $13 \pm 0,00$ (years), the size was $162,5 \pm 8,23(\mathrm{~cm})$ and the mean weight was $54,48 \pm 9,17(\mathrm{~kg})$; The mean age of the control group was $13 \pm 0,00$ years, and the mean was $162,15 \pm 11,17(\mathrm{~cm})$ and the mean weight was 53,25 $\pm 9,90(\mathrm{~kg})$.

\subsection{Training Method}

The study is planned for 8 weeks in Turkey Kocaeli Metropolitan Municipality Sports Health Performance Test and Analysis Center by taking the age, height, weight, standing horizontal jump, vertical jump, left and right hand grip, sitting - reaching out distance and lying down-reaching distance flexibility measurements of the athletes. After the first measurements, the athletes divided into two as experimental $(\mathrm{n}=10)$ and control $(\mathrm{n}=10)$ groups; While only daily unit technical tactical trainings were applied to the control group, plyometric training was applied to the experimental group as well as daily unit training according to their training program (Table 1). Before the training program was implemented, the athletes were given information about the purpose of the study in order to do make them work effectively, by increasing their desire on applying the program and their motivation levels. Before the tests were done, athletes were heated for 15 minutes to get ready for loading. In order to make the tests productive and not face with disability during the tests, Jog and stretching exercises were applied. The training program was conducted for 8 weeks period for both groups.

Table 1. 8-Week Plyometric Training Program

\begin{tabular}{|c|c|c|c|c|c|c|}
\hline \multirow[b]{2}{*}{ Week } & \multirow{2}{*}{$\begin{array}{c}\text { Plyometric Training } \\
\text { Program }\end{array}$} & \multirow{2}{*}{$\begin{array}{c}\text { Sets x } \\
\text { Repeats }\end{array}$} & \multicolumn{2}{|c|}{ Rest (min) } & \multirow{2}{*}{$\begin{array}{c}\text { Intensity } \\
\text { (\%)/Extent } \\
\text { (Number) }\end{array}$} & \multirow{2}{*}{$\begin{array}{c}\text { Number } \\
\text { Of } \\
\text { Training }\end{array}$} \\
\hline & & & $\begin{array}{c}\text { Between } \\
\text { Series }\end{array}$ & $\begin{array}{c}\text { Between } \\
\text { Sets }\end{array}$ & & \\
\hline \multirow{4}{*}{$1-2$} & Warming Jump & $1 \times 15$ & 1 & 2 & \multirow{4}{*}{$\begin{array}{c}50 \% / \\
90\end{array}$} & \multirow{4}{*}{4} \\
\hline & Half Squat Jump & $2 \times 15$ & 1 & 2 & & \\
\hline & Quarter Squat Jump & $2 \times 15$ & 1 & 2 & & \\
\hline & Lunge Jump & $1 \times 15$ & 1 & 2 & & \\
\hline \multirow{4}{*}{$3-4$} & Warming Jump & $1 \times 20$ & 1 & 2 & \multirow{4}{*}{$\begin{array}{c}60 \% / \\
120\end{array}$} & \multirow{4}{*}{4} \\
\hline & Half Squat Jump & $2 \times 20$ & 1 & 2 & & \\
\hline & Quarter Squat Jump & $2 \times 20$ & 1 & 2 & & \\
\hline & Lunge Jump & $1 \times 20$ & 1 & 2 & & \\
\hline \multirow{4}{*}{$5-6$} & Warming Jump & $1 \times 20$ & 1 & 2 & \multirow{4}{*}{$\begin{array}{c}70 \% / \\
160\end{array}$} & \multirow{4}{*}{4} \\
\hline & Half Squat Jump & $3 \times 20$ & 2 & 2 & & \\
\hline & Quarter Squat Jump & $3 \times 20$ & 2 & 2 & & \\
\hline & Lunge Jump & $1 \times 20$ & 1 & 2 & & \\
\hline \multirow{4}{*}{$7-8$} & Warming Jump & $1 \times 20$ & 1 & 2 & \multirow{4}{*}{$\begin{array}{c}80 \% / \\
160\end{array}$} & \multirow{4}{*}{4} \\
\hline & Half Squat Jump & $3 \times 20$ & 2 & 2 & & \\
\hline & Quarter Squat Jump & $3 \times 20$ & 2 & 2 & & \\
\hline & Lunge Jump & $1 \times 20$ & 1 & 2 & & \\
\hline
\end{tabular}




\subsection{Measurements}

Descriptive statistical values (age, height, weight) of the group consisting of totally 20 athletes were taken. Vertical Jump test was performed for and Takei 5406 Vertical Jump Meter was used in tests. Standing Long Jump Test; the volunteers were asked to jump from one fixed point to the next as they could skip double legs in parallel position. Measuring jump the last track left by the volunteer was done with a steel tape measure. Participants were given two jumps and the best calculations were taken into account. For the flexibility measurements; the seated lying and lying-reaching elastic flexibility tests were applied and the table scales were used. Hand grip performance measured by Hand Grip Dynamometer (Takei Japan) that precision at 0-100 kg.

\subsection{Data Analysis}

In the study, the data of the first and the last test measurements of the experimental and control groups before and after the 8 -week training program were analysed at the level of 0.05 significance level in SPSS 18.0 program on computer. In the statistical analysis of the study, descriptive statistics as minimum and maximum values and arithmetic mean and standard deviation values were taken. Wilcoxon test was used for when comparing dependent groups and Mann - Whitney U test was used to compare the independent groups.

\section{Results}

Table 2. First Measurement Analysis Table Of Control And Experimental Group

\begin{tabular}{|c|c|c|c|c|c|c|c|}
\hline First Measurements & Groups & $\mathbf{N}$ & Minimum & Maximum & Mean & $\begin{array}{l}\text { Standard } \\
\text { Deviation }\end{array}$ & $\mathbf{P}$ \\
\hline \multirow{2}{*}{ Vertical Jump (cm) } & Experimental & 10 & 30 & 47 & 36,5 & 4,58 & \multirow{2}{*}{0,88} \\
\hline & Control & 10 & 29 & 46 & 36,6 & 4,58 & \\
\hline \multirow{2}{*}{ Long Jump (cm) } & Experimental & 10 & 133 & 211 & 170 & 23,26 & \multirow{2}{*}{0,21} \\
\hline & Control & 10 & 125 & 197 & 158,5 & 20,71 & \\
\hline \multirow{2}{*}{ Right Hand Grip (kg) } & Experimental & 10 & 19,7 & 46,2 & 26,59 & 7,75 & \multirow{2}{*}{0,71} \\
\hline & Control & 10 & 17,7 & 38,8 & 25,48 & 6,81 & \\
\hline \multirow{2}{*}{ Left Hand Grip (kg) } & Experimental & 10 & 16,4 & 48,8 & 26,05 & 8,83 & \multirow{2}{*}{0,52} \\
\hline & Control & 10 & 16,6 & 34,4 & 23,77 & 5,51 & \\
\hline \multirow{2}{*}{ Sit-Reach Flexibility Test (cm) } & Experimental & 10 & -2 & 10 & 5,5 & 4,25 & \multirow{2}{*}{1} \\
\hline & Control & 10 & -2 & 10 & 5,5 & 4,25 & \\
\hline \multirow{2}{*}{$\begin{array}{l}\text { Standing-Reach } \\
\text { (cm) }\end{array}$} & Experimental & 10 & $-5,5$ & 9,8 & 1,57 & 5,06 & \multirow{2}{*}{0,11} \\
\hline & Control & 10 & -3 & 13 & 5,6 & 5,85 & \\
\hline
\end{tabular}

As shown in table 2, there was no significant difference between the groups in the results of the first measurements of vertical jump (control group 36,6 $\pm 4,58 /$ experimental group 36,5 $\pm 4,58$ ), long jump (control group158,5 $\pm 20,71$ / experimental group 170 $\pm 23,26$ ), right hand grip (control group 25,48 $\pm 6,81$ / experimental group 26,59 $\pm 7,75$ ), left hand

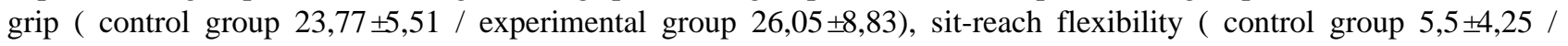
experimental group 5,5 $\pm 4,25$ ) and Standing-Reach Flexibility (control group 5,6 $\pm 5,85 /$ experimental group 1,57 $\pm 5,06$ ) (p>0.05), groups were homogeneous and no difference was found. 
Table 3. First-Last Measurement Wilcoxon Analysis Table Of Control Group

\begin{tabular}{|c|c|c|c|c|c|c|}
\hline Control Group Measurements & $\mathbf{N}$ & Minimum & Maximum & Mean & $\begin{array}{l}\text { Standard } \\
\text { Deviation }\end{array}$ & $\mathbf{P}$ \\
\hline Vertical Jump First (cm) & 10 & 29 & 46 & 36,6 & 4,57 & \multirow{2}{*}{0,799} \\
\hline Vertical Jump Last (cm) & 10 & 25 & 41 & 36 & 5,05 & \\
\hline Long Jump First (cm) & 10 & 125 & 197 & 158,5 & 20,7 & \multirow{2}{*}{0,833} \\
\hline Long Jump Last (cm) & 10 & 130 & 189 & 159,3 & 19,61 & \\
\hline Right Hand Grip First (kg) & 10 & 17,7 & 38,8 & 25,48 & 6,81 & \multirow{2}{*}{0,05} \\
\hline Right Hand Grip Last (kg) & 10 & 15,7 & 34,4 & 24,02 & 6 & \\
\hline Left Hand Grip First (kg) & 10 & 16,6 & 34,1 & 23,77 & 5,5 & \multirow{2}{*}{0,944} \\
\hline Left Hand Grip Last (kg) & 10 & 12,7 & 35 & 23,58 & 6,52 & \\
\hline Sit-Reach Flexibility Test First (cm) & 10 & -2 & 10 & 5,5 & 4,25 & \multirow{2}{*}{$\mathbf{0 , 0 1 3 *}$} \\
\hline Sit-Reach Flexibility Test Last (cm) & 10 & -12 & 10 & $-0,5$ & 6,57 & \\
\hline $\begin{array}{l}\text { Standing-Reach Flexibility Test First } \\
\text { (cm) }\end{array}$ & 10 & -3 & 13 & 5,6 & 5,05 & \multirow{2}{*}{0,103} \\
\hline $\begin{array}{l}\text { Standing-Reach Flexibility Test First } \\
\text { (cm) }\end{array}$ & 10 & $-4,6$ & 10,5 & 3,5 & 5,05 & \\
\hline
\end{tabular}

As seen in table 3, there was a significant difference in the negative value of the control group first and last measurements sit-reach test result $(\mathrm{p}<0.05)$, but no statistically significant difference was found first and last vertical jump, long jump, right and left hand grip, standing-reach flexibility measurements $(\mathrm{p}>0.05)$.

Table 4. First-Last Measurement Wilcoxon Analysis Table Of Experimental Group

\begin{tabular}{|c|c|c|c|c|c|c|}
\hline Experımental Group Measurements & $\mathbf{N}$ & Minimum & Maximum & Mean & $\begin{array}{l}\text { Standard } \\
\text { Deviation }\end{array}$ & $\mathbf{P}$ \\
\hline Vertical Jump First (cm) & 10 & 30 & 47 & 36,5 & 4,57 & \multirow{2}{*}{0,33} \\
\hline Vertical Jump Last (cm) & 10 & 30 & 47 & 36,4 & 4,4 & \\
\hline Long Jump First (cm) & 10 & 133 & 211 & 170 & 23,26 & \multirow{2}{*}{0,44} \\
\hline Long Jump Last (cm) & 10 & 131 & 208 & 168,1 & 23,87 & \\
\hline Right Hand Grip First (kg) & 10 & 19,7 & 46,2 & 26,59 & 7,74 & \multirow{2}{*}{0,14} \\
\hline Right Hand Grip Last (kg) & 10 & 19,3 & 47,5 & 27,53 & 8,82 & \\
\hline Left Hand Grip First (kg) & 10 & 16,4 & 48,8 & 26,05 & 8,31 & \multirow{2}{*}{0,52} \\
\hline Left Hand Grip Last (kg) & 10 & 17,6 & 48,5 & 26,56 & 8,93 & \\
\hline Sit-Reach Flexibility Test First (cm) & 10 & -2 & 10 & 5,5 & 4,24 & \multirow{2}{*}{0,12} \\
\hline Sit-Reach Flexibility Test Last (cm) & 10 & -5 & 9 & 2,6 & 4,52 & \\
\hline $\begin{array}{l}\text { Standing Sit-Reach Flexibility Test First } \\
\text { (cm) }\end{array}$ & 10 & $-5,5$ & 9,8 & 1,57 & 5,05 & \multirow{2}{*}{1} \\
\hline $\begin{array}{l}\text { Standing Sit-Reach Flexibility Test Last } \\
(\mathrm{cm})\end{array}$ & 10 & $-5,5$ & 9,8 & 1,57 & 5,05 & \\
\hline
\end{tabular}

As shown in Table 4, there was no statistically significant difference between the first and last vertical jump, long jump, right and left hand grip, sit-reach and standing-reach flexibility measurements in experimental group ( $\mathrm{p}>0.05)$. 
Table 5. First-Last Measurement Analysis Table Of Control And Experimental Group

\begin{tabular}{|c|c|c|c|c|c|c|c|}
\hline Last Measurements & Groups & $\mathbf{N}$ & Minimum & Maximum & Mean & $\begin{array}{l}\text { Standard } \\
\text { Deviation }\end{array}$ & $\mathbf{P}$ \\
\hline \multirow{2}{*}{ Vertical Jump (cm) } & Experimental & 10 & 30 & 47 & 36,4 & 4,4 & \multirow{2}{*}{0,62} \\
\hline & Control & 10 & 25 & 41 & 36 & 5,06 & \\
\hline \multirow{2}{*}{ Long Jump (cm) } & Experimental & 10 & 131 & 208 & 168,1 & 23,87 & \multirow{2}{*}{0,4} \\
\hline & Control & 10 & 130 & 189 & 159,3 & 19,62 & \\
\hline \multirow{2}{*}{ Right Hand Grip (kg) } & Experimental & 10 & 19,3 & 47,5 & 27,53 & 8,32 & \multirow{2}{*}{0,36} \\
\hline & Control & 10 & 15,7 & 34,1 & 24,02 & 6 & \\
\hline \multirow{2}{*}{ Left Hand Grip (kg) } & Experimental & 10 & 17,6 & 48,5 & 26,56 & 8,94 & \multirow{2}{*}{0,68} \\
\hline & Control & 10 & 12,7 & 35 & 23,58 & 6,52 & \\
\hline \multirow{2}{*}{ Sit-Reach Flexibility Test (cm) } & Experimental & 10 & -5 & 9 & 2,6 & 4,53 & \multirow{2}{*}{0,26} \\
\hline & Control & 10 & -12 & 10 & $-0,5$ & 6,57 & \\
\hline \multirow{2}{*}{$\begin{array}{l}\text { Standing } \\
\text { Test (cm) }\end{array}$} & Experimental & 10 & $-5,5$ & 9,8 & 1,57 & 5,06 & \multirow{2}{*}{0,36} \\
\hline & Control & 10 & $-4,6$ & 10,5 & 3,5 & 4,96 & \\
\hline
\end{tabular}

As shown in Table 5, as a result of the statistical analysis, no statistically significant difference was found between the experimental and control groups according to the final test data ( $\mathrm{p}>0.05)$. Last measurement average values are vertical

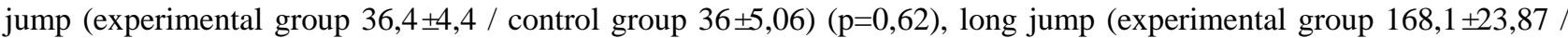
control group 159,3 $\pm 19,62)(\mathrm{p}=0,4)$, right hand grip (experimental group 27,53 $\pm 8,32$ / control group 24,02 \pm 6$)(\mathrm{p}=0,36)$, left hand grip (experimental group 26,56 $\pm 8,94$ / control group 23,58 $\pm 6,52)(\mathrm{p}=0,68)$, sit-reach flexibility (experimental

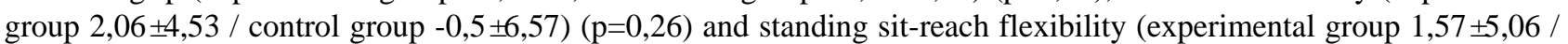
control group $3,5 \pm 4,96)(\mathrm{p}=0,36)$.

\section{Discussion}

In this study, the effects of plyometric exercises applied to male athletes playing in U13 basketball league on vertical-horizontal jump and right-left hand claw strength, sit-down and back-up elasticity tests were investigated. As a result of the study, the results of the vertical jump measurement analysis of the control group athletes who applied basketball technique-tactical training program for 2 times/week during 8 weeks $(-0.6 \mathrm{~cm}$ difference $) \mathrm{p}=0.799$, long jump by standing $(+1 \mathrm{~cm}$ difference) $\mathrm{p}=0.833$, right hand grip $(-1,46 \mathrm{~kg}$ difference $) \mathrm{p}=0,05$, left hand grip ( $-0,19 \mathrm{~kg}$ difference) $\mathrm{p}=0,944$, sit-down-reach test $(-4 \mathrm{~cm}$ difference) $\mathrm{p}=0,013$ and lying-reach test measurements $(-2.1 \mathrm{~cm}$ difference) $\mathrm{p}=0.103$ was determined. It can be said that the decrease in the measurement values of the control group is due to the lack of coordination brought by the age of puberty.

As a result of the study, experimental group of athletes who applied the 15-minute plyometric training program in the basketball technical - tactical training program who applied 2 days/week during for 8 weeks; the vertical jump measurement analysis were determined as $(-0,01 \mathrm{~cm}$ difference $) \mathrm{p}=0,322$, long jump $(-2 \mathrm{~cm}$ difference $) \mathrm{p}=0,440$, right hand grip $(0,94 \mathrm{~kg}$ difference $) \mathrm{p}=0,139$, left hand grip $(+0,01 \mathrm{~kg}$ difference $) \mathrm{p}=0,515$, sit-down-lying test ( $-2,9 \mathrm{~cm}$ difference) $\mathrm{p}=0,112$ and lying reach test results $(0 \mathrm{~cm}$ difference $) \mathrm{p}=1$. As the 15 -minute plyometric training was not effective, there was no significant improvement in the jump performance due to the inability to provide sufficient force development in the muscle development parallel to the bone development brought by the adolescence, since it could not control the extremities and could not provide the spatial coordination.

Plyometric trainings are effective in soccer players' physical fitness values, in exercise group; strength, reaction, vertical jump and standing-long jump values (Ağılönü and Kıratlı, 2015), in lower limb (jump, agility and sprint grades) parameters of high school students, it was effective even in 6 week periods ( Asadi and Ramirez-Campillo, 2016), by the study performed on basketball players; it was found that there was a significant difference in the vertical jump performance in the experimental group (Bavl1, 2012), and it is detected that a strong relationship between the force applied to volleyball\& handball athletes and the effect of plyometric trainings on explosive power (Cezar, et. al., 2013). In his study on the effect of plyometric exercises on motor skill applied to young female soccer players, it was determined that squat jump (3.3\% increase), long jump (5.3\%) measurements were improved (Claudiu, 2015), lower extremity plyometric training had an effect on skill ( $\mathrm{T}$ test, Ilinoi and Force Plate skill tests ( $\mathrm{p}<0.05$ ), also only in professional athletes to prevent the monotony of training and also positively affect the development of explosive power (Miller, et al., 2006), There were significant changes on basketball players who has taken 8 weeks of plyometric 
training as vertical jump, horizontal jump, $30 \mathrm{~m}$ velocity, anaerobic power, $20 \mathrm{~m}$ shuttle, body density, body fat percentage and lean body weight $(\mathrm{p}<0.01)$, but no difference was found between the force and plyometric group at the end of the study ( $p>0.05$ ) (Öztin et al., 2003). In the studies conducted on the lower extremity muscle EMG changes in the futsal players who applied 4 weeks of plyometric training, there was an increase in the EMG values in the application of squat motion $(\mathrm{p}<0.05)$ but there was no significant difference in the vertical jump motion $(\mathrm{p}>0.05)$ (Rezaimanesh, et al., 2011). At the end of plyometric and resistant plyometric trainings applied to athletes who play basketball for 12 weeks, 5 days/week (in 3 days of 5 days, the mentioned plyometric and resistant plyometric trainings were applied) vertical jump values were not found to be different within group and intergroup analysis results; elasticity values were improved within group ( $p<0.05$ ) but not improved intergroup ( $p>0.05)$ (Pamuk, 2017).

While there was a significant difference in the flexibility, horizontal jump, vertical jump and right / left hand grip strength measurement of the experimental group of plyometric studies applied to 10 weeks, 2 days a week and 60 minutes for 12-14 aged primary school children ( $\mathrm{p}<0.05$ ); there was no significant difference in the control group (who has taken Physical Education lessons) ( $p>0,05$ ) (Çavdar, 2006), plyometric and weighted plyometric trainings in the anaerobic and vertical jump performance of both groups of athletes in the flexibility and vertical jump values were found significantly different ( $\mathrm{p}<0,05)$ (Gençay, 2014). Plyometric trainings applied to active basketball players with an average age of 15-18 ages were found to be significantly different in free jump $(\mathrm{cm}), 120^{\circ}$ squat jump $(\mathrm{cm})$ and active jump $(\mathrm{cm})$ values of all athletes (experiment / control). Plyometric trainings applied to active basketball players with an average age of 15-18 were found to be significantly different in free jump $(\mathrm{cm}), 120^{\circ}$ squat jump $(\mathrm{cm})$ and active jump $(\mathrm{cm})$ values of all athletes (experiment / control). When the free jump (cm) parameter is examined, it is observed that the development of the experimental group was $8.51 \%, 4.77 \%$ in the control group, 120 degrees squat jump parameter was $13.03 \%$ in the experimental group, $5.40 \%$ in the control group; $8.72 \%$ in the active jump parameter experiment group, control group was found to be $4.22 \%$ (Adigüzel, 2017). As a result of the added weight in-water and ground plyometric training applied to $15-17$ age basketball players, standing-on long jump (water: $12.50 \%$; ground: $14.45 \mathrm{~cm}$ ), vertical jump (water: 9\%; land: $8.27 \%$ ) ) and right grip (water: 3,96\%; land: 4,26 kg) and left grip (water: 4,63\%; land: $3,86 \mathrm{~kg}$ ) were statistically significant difference $(\mathrm{p}<0,05)$ (Cigerci, 2017).

The plyometric training performed for average age of the $23.89 \pm 4.71$ years (mean) basketball athletes during 5 months, the vertical jump in the experimental group measurement values of each month between the first month and the fifth month has been found to increase meaningfully (1st Measurement $49.90 \pm 10,08 \mathrm{~cm}$; 5 th measurement $56 \pm 10.33 \mathrm{~cm}$ ) $(\mathrm{p}<0.05)$ (Güneş, 2008), a significant difference was found between the test group vertical and horizontal jumping tests, $20 \mathrm{~m}$ sprint, 505 skill test and overhead ball-throw test results for plyometric training sessions performed during 8 weeks for young tennis players aged 12-13 years ( $\mathrm{p}<0.05$ ) (Fernandez-Fernandez, et al., 2015). It was found that plyometric and interval training performed with 14-16 year old girls\&boys basketball players had a significant difference in the vertical jump value of both groups (Göllü, 2006), basketball players aged 12-14 years (Kızllet et al., 2010) and 14 - 16 years old badminton athletes (Aygül, 2010) applied plyometric training results showed a significant difference in horizontal jump for intra-group and inter-group comparisons ( $p<0,05)$, it was found that an effect of horizontal jump on $22,45 \pm 5,22$ (years) mean age of basketball players applied plyometric training on the vibration device ( $\mathrm{p}<0,05)$ (Usgu, 2016), it was concluded that the result of the exercises applied to volleyball players has improved their jump performance ( $\mathrm{p}<0.05$ ) (Çimenli, 2011).

As a result, in this study, it is understood that there is no effect the 15-minute plyometric training program basketball technique-tactical training program for 2 weeks a week for 8 weeks, the effect of the children who play basketball in the 13 years age group on the vertical and horizontal jumping, right and left grip strength, sit-down and height-elasticity test measurements.

\section{References}

Adıgüzel, N. S. (2017). The Effect of Eight-Week Plyometric Training on Leaping and Isokinetic Force Parameters in Basketball Players in the 15-18 Age Group. Gazi University Institute of Health Sciences. Department of Physical Education and Sports. PhD Thesis, 69-82.

Ağılönü, A., \& Kıratlı, G. (2015). Investigation of the effect of 8-week plyometric training on some physical fitness parameters of 12-16 year-old female handball players. International Journal of Human Sciences, 12(1), 1216-1228. https://doi.org/10.14687/ijhs.v12i1.3207

Asadi, A., \& Ramirez-Campillo, R. (2016). Effects of cluster vs. traditional plyometric training. Medicana, 52, 41-45. https://doi.org/10.1016/j.medici.2016.01.001

Ateş, M., \& Ateşoğlu, U. (2007). The effect of plyometric training on male and lower extremity force parameters of 16-18 age group men. Nigde University Journal of Physical Education and Sport Sciences, 1(1), 1-12. 
Aygül, M. (2010). The effect of plyometric training program on motoric features in women aged 14-16. Niğde: Niğde University, Institute of Social Sciences, Department of Physical Education and Sports, Master Thesis.

Bavlı, Ö. (2009). Effect of pool plyometric exercises and field plyometric exercises on biomotoric and structural characteristics of adolescent period basketball players. Çukurova University, Institute of Health Sciences, $\mathrm{PhD}$ Thesis.

Bavlı, Ö. (2012). the effect of plyometric combinations on basketball biomotor properties. Journal of Sport Sciences $3(2), 90-100$.

Çavdar, K. (2006). Investigation of students performing plyometric training. Marmara University Health Sciences Institute. Department of Physical Education and Sports, Master Thesis. 67-116.

Cezar, H., Doina, C., Dan, B., \& Gheorghe, G. (2013). Study concerning the developing of the explosive strength in sport games, procedia. Social and Behavioral Sciences. 93, 1922-1925. https://doi.org/10.1016/j.sbspro.2013.10.141

Cigerci, A. E. (2017). The effect of extra weight applied water and black plyometric trainings on some physical and physiological characteristics of 15-17 age group basketball players. Gazi University Institute of Health Sciences. Department of Physical Education and Sports. PhD Thesis, 53-64.

Claudiu, M. (2015). The role of plyometric exercises in the physical preparation of junior female football players. Procedia - Social and Behavioral Sciences, 180, 1257-1262. https://doi.org/10.1016/j.sbspro.2015.02.261

Dündar, U. (1990). Basketball is the condition. Ankara: Bağırgan Publishing.

Ermiş, E., \& Imamoglu, O. (2002). To investigate the effects of physical, physiological and technical characteristics of high school basketball players on matches. 7. International Sport Sciences Congress, 27-29 October, poster paper, No: 155.

Fernandez-Fernandez, J., Villarreal, E. S., Sanz-Rivas, D., \& Moya, M. (2015). The effects of 8-week plyometric training on physical performance in young tennis players. Human Kinetics Journals, Pediatric Exercise Science, 28(1), 77-86. https://doi.org/10.1123/pes.2015-0019

Gençay, E. (2014). The effect of two different plyometric trainings on 8 week anaerobic performance and vertical splash in amateur athletes. Dumlupinar University, Institute of Health Sciences, Department of Physical Education and Sports. Master Thesis. 35-53.

Göllü, G. (2006). 14-16 years old girls and boys basketball students only two months with plyometric or plyometric common interyal training program on the physiological values of the application of the effect. Eskişehir Osmangazi University, Institute of Health Sciences, Master thesis. 62-142.

Güneş, T. D. (2008). Investigation of the effect of customized modern plyometric training on motor development in basketball. Marmara University Health Sciences Institute. Department of Physical Education and Sports. Master Thesis, 48-62.

Kizılet, A. A. (2010). The effect of different strength training on the quickness and jump skills of 12-14 age group basketball players. Atabesbd, 12(2), 44-57.

Markovic, G. (2007). Does plyometric training improve vertical jump height? A meta-analytical review. British Journal of Sports Medicine, 41, 349 Medicine 355. https://doi.org/10.1136/bjsm.2007.035113

Miller, M. G., Herniman, J. J., Ricard, M. D., Cheatham, C. C., \& Michael, T. J. (2006). The effects of a 6-week plyometric trainıng program on agility. Journal Of Sports Science And Medicine, 5, 459-465.

Öztin, S., Erol, A.E., \& Atilla, P. (2003). 15-16 age group basketball athletes on the physical and physiological features of the quick force and plyometric studies. Journal of Gazi Body and Sport Sciences (Gazi Besbd), 1, 41-52.

Pamuk, Ö. (2017). Effect of resistant plyometric training on physical performance and pain parameters in athletes. Akdeniz University, Institute of Health Sciences, Department of Sport Sciences. PhD Thesis, 44-55.

Rezaimanesh, D., Amiri-Farsani, P., \& Saidian, S. (2011). The effect of a 4 week plyometric training period on lower body muscle emg changes in futsal players. Procedia Social And Behavioral Sciences, 15, 3138-3142. https://doi.org/10.1016/j.sbspro.2011.04.260

Salonikidis, K., \& Zafeiridis, A. (2008). The effects of plyometrıc, tennıs-drills, and combined training on reaction, lateral and linear speed, power, and strength in novice tennis players. Journal Of Strength And Conditioning Research, National Strength And Conditioning, 22(1), 182-191. https://doi.org/10.1519/JSC.0b013e31815f57ad 
Slimani, M., Paravlic, A., \& Bragazzi, N. L. (2017). Data concerning the effect of plyometric training on jump performance in soccer players: A meta-analysis. Data in Brief, 15(2017), 324-334. https://doi.org/10.1016/j.dib.2017.09.054

Usgu, G. (2016). Effects of plyometric training on vibration performance in basketball players. Hacettepe University, Institute of Health Sciences, Department of Physiotherapy and Rehabilitation, PhD Thesis. 40-65.

Villarreal, E. S., Requena, B., \& Newton, U. R. (2015). Does plyometric training improve strength performance? A meta-analysis. Journal Of Science And Medicine In Sport, 13, 513-522. https://doi.org/10.1016/j.jsams.2009.08.005

Yüksel, Y. (2016). Plyometric exercise. Journal of Human Sciences, 13(3), 5605-5612. https://doi.org/10.14687/jhs.v13i3.4131

\section{Copyrights}

Copyright for this article is retained by the author(s), with first publication rights granted to the journal.

This is an open-access article distributed under the terms and conditions of the Creative Commons Attribution license which permits unrestricted use, distribution, and reproduction in any medium, provided the original work is properly cited. 